\title{
Seleção do Comportamento por Justificativas Constituintes de Regras
}

\author{
Luiz Carlos de Albuquerque ${ }^{1}$ \\ Carla Cristina Paiva Paracampo \\ Universidade Federal do Pará, Belém, PA, Brasil
}

\begin{abstract}
Resumo
Considerando que a distinção entre os efeitos de estímulos constituintes de regras e de contingências de reforço na determinação do comportamento não está clara, o presente estudo teve como objetivo tentar esclarecer essa distinção por meio da apresentação da teoria do Controle por Justificativas e por Consequências Imediatas (Teoria TJC). Essa teoria, baseada em resultados experimentais, é constituída dos seguintes conceitos, formulados em estudos prévios: Propriedade formal de estímulos verbais; regras; comportamento; ambiente social; ambiente social verbal; ambiente social não verbal; consequências imediatas; consequências futuras; justificativas; justificativas dos Tipos 1, 2, 3, 4 e 5; aprovação ou desaprovação por justificativas e por consequências imediatas; regras com e sem justificativas relatadas; eventos futuros passíveis e não passíveis de serem contatados; e, histórias do ouvinte de controle: (a) por consequências imediatas diferenciais, (b) por justificativas diferenciais, e (c) pela interação entre justificativas e consequências imediatas diferenciais, para seguir e para não seguir regra. A Teoria postula o estabelecimento de limites entre o que deve ser atribuído a funções de estímulos constituintes de regras e entre o que deve ser atribuído a funções de estímulos constituintes de contingências de reforço. Postula também que justificativas podem selecionar comportamento.
\end{abstract}

Palavras-chave: Comportamento governado por regras, comportamento modelado por contingências de reforço, justificativas, consequências imediatas, teoria.

\section{Selection of Behavior by Justifications as Constituent of Rules}

\begin{abstract}
Considering that the distinction between the effects of stimuli that are constituent of rules and of reinforcement contingencies in the determination of behavior is not clear, this study attempts to clarify such a distinction by the presentation of the Theory of Control by Justifications and by Immediate Consequences (TJC Theory). This theory, grounded in experimental results, comprises the following concepts, as defined in previous studies: formal properties of verbal stimuli; rules; behavior; social environment; verbal social environment; nonverbal social environment; immediate consequences; justifications; justification Types 1, 2, 3, 4, and 5; approval or disapproval by justification and by immediate consequences; rules with and without reported justifications; future events that may or may not be contacted; and control histories of the listener by (a) immediate differential consequences, (b) differential justifications,
\end{abstract}

Endereço para correspondência: Av. Gov. José Malcher, 163/Apto. 06 - B, Nazaré, Belém, PA, Brasil 66035100.E-mail: 1calbu@ufpa.br

Trabalho realizado com auxílio do Conselho Nacional de Desenvolvimento Científico e Tecnológico (CNPq), em forma de concessão de bolsa de produtividade em pesquisa aos dois autores. 
and (c) the interaction between justifications and immediate differential consequences for following rules and for not following rules. The theory postulates the establishment of limits between what should be attributed to functions of stimuli as constituent of rules and what should be attributed to functions of stimuli as constituent of reinforcement contingencies. TJC Theory also postulates that justification can select behavior.

Keywords: Rule governed behavior, contingency-shaped behavior, justifications, imediate consequences, theory.

\section{Selección de Comportamientos por Justificaciones Constituyentes de Reglas}

\section{Resumen}

Considerando la distinción entre los efectos de las reglas constituyentes de estímulos y contingencias de reforzamiento en la determinación del comportamiento no es claro, este estudio tuvo como objetivo tratar de aclarar esta distinción mediante la presentación de la teoría de Control por Justificaciones y por Consecuencias Inmediatas (Teoría TJC). Esta teoría, basándose en los resultados experimentales, se compone de los seguientes conceptos, formulados en estudios anteriores: propiedad formal de estímulos verbales; reglas; comportamiento; entorno social verbal; entorno social no verbal; consecuencias inmediatas; consecuencias futuras; justificaciones; justificaciones de los Tipos 1, 2, 3, 4 y 5; aprobación o desaprobación por justificaciones y por consecuencias inmediatas; reglas con y sin justificaciones reportadas; eventos futuros con o sin la posibilidad de ser contactados; y, historias del oyente, de control: (a) por consecuencias inmediatas diferentes, (b) por justificaciones diferentes, y (c) por la interacción entre justificaciones y consecuencias inmediatas distintas, para seguir y para no seguir la regla. La teoría postula el establecimiento de límites entre lo que debe ser asignado a funciones de estímulos constituyentes de reglas y entre lo que debe ser asignado a funciones de estímulos contituyentes de contingencias de refuerzo. También postula que las justificaciones pueden seleccionar el comportamiento.

Palabras clave: Comportamiento gobernado por reglas, comportamiento modelado por las contingencias de refuerzo, justificaciones, consecuencias inmediatas, teoría.

\section{Funções de Regras}

Skinner (1963, 1966, 1969), quando introduziu na literatura a distinção entre o comportamento governado por regras e o comportamento modelado por contingências, definiu regras como estímulos especificadores de contingências que funcionam como estímulos discriminativos. Por essa definição, instruções, avisos, orientações, conselhos, ordens e leis, dentre outros, seriam exemplos particulares de regras, uma vez que todos podem descrever contingências, isto é, podem descrever as relações de interdependência entre os eventos que antecedem o comportamento, o próprio comportamento e suas prováveis consequências. Regras ocasionam comportamento porque o comportamento de seguir regras similares foi reforçado no passado. De acordo com essa proposição, o ambiente funciona de duas maneiras: ele modela e mantém repertórios de comportamento (função exercida pelas consequências do comportamento) e estabelece a ocasião para que o comportamento ocorra (função exercida pelos estímulos discriminativos, cujas funções seriam estabelecidas pelas consequências do comportamento; Skinner, 1989). Regras, assim, funcionariam como estímulos discriminativos fazendo parte de um conjunto de contingências de reforço (Skinner, 1969).

$\mathrm{Na}$ análise do comportamento, essa proposição de Skinner (1969) tem sido defendida (Baron \& Galizio, 1983; Cerutti, 1989; Galizio, 1979; Okougui, 1999), mas ela não encontra unanimidade (Albuquerque, Paracampo, Mat- 
suo, \& Mescouto, 2013; Malott, 1989; Schlinger \& Blakely, 1987; Zettle \& Hayes, 1982).

Zettle e Hayes (1982), por exemplo, argumentam que a proposição de Skinner (1969) não deixa claro o que significa especificar contingências e desconsidera exemplos de regras que não especificam claramente contingências de reforço. Propuseram, então, que regras deveriam ser definidas como estímulos antecedentes verbais. Para os autores, essa definição tem as vantagens de evitar o problema do que significa especificar contingências e de incorporar regras que não especificam claramente contingências.

Já Schlinger e Blakely (1987) argumentam que regras não funcionam como estímulos discriminativos, porque elas não evocariam comportamento. Regras funcionariam como estímulos alteradores de função de outros estímulos. Segundo esses autores, estímulos discriminativos evocam comportamento imediatamente, ao passo que os efeitos de regras são observados, frequentemente, depois de certo tempo. Considere, por exemplo, um ouvinte que foi exposto à seguinte regra: "Mande a Maria estudar matemática, quando ela chegar". Nesse exemplo a regra não evoca o comportamento por ela descrito, isto é, a ouvinte não emite o comportamento descrito pela regra (mandar a Maria estudar matemática) imediatamente após entrar em contato com a regra. $\mathrm{O}$ que evoca o comportamento descrito pela regra é o estímulo descrito pela regra (a chegada da Maria). Nesse caso, pode-se sugerir que a regra estabeleceu a função discriminativa do estímulo por ela descrito (a chegada da Maria) para o comportamento por ela descrito (mandar a Maria estudar matemática). Dessa forma, a chegada da Maria se tornaria um estímulo discriminativo, não devido a uma história de reforço diferencial do comportamento de mandar a Maria estudar matemática na sua presença, mas sim devido à sua participação prévia na regra.

De acordo com Schlinger e Blakely (1994), o ambiente também funciona de duas maneiras: evoca comportamento e altera a função evocativa dos estímulos. O termo evocar deveria ser usado para descrever o efeito de um evento em produzir mudança momentânea na frequência do comportamento. Por exemplo, para descrever o efeito produzido, sobre o comportamento, por estímulos incondicionados, estímulos condicionados, estímulos discriminativos e operações motivadoras. Já o termo alterador de função deveria ser usado para descrever a maneira pela qual a história dos indivíduos estabelece, modifica e mantém as funções evocativas dos estímulos. Por exemplo, para descrever o efeito produzido pelo condicionamento respondente (um estímulo neutro adquire a função de estímulo condicionado quando, sob algumas condições, ele é emparelhado a um estímulo incondicionado), condicionamento operante (um estímulo adquire a função de estímulo discriminativo como resultado de uma história de reforço diferencial do comportamento na sua presença), equivalência de estímulos (transferência de funções de estímulos como resultado de uma história de reforço e de treino em um procedimento de emparelhamento com o modelo) e estímulos verbais (podem produzir efeitos análogos aos do condicionamento respondente e aos do condicionamento operante).

Para Malott (1989), regras funcionam como estímulos discriminativos, visto que elas podem evocar comportamento e, como operações estabelecedoras, uma vez que elas podem tornar as consequências comportamentais mais reforçadoras ou mais aversivas. As funções de regras resultam da história comportamental de reforço da obediência à regra e de punção da desobediência à regra.

De acordo com Albuquerque et al. (2013), regras têm três propriedades definidoras: (a) a propriedade formal ${ }^{2}$ de poderem descrever o

\footnotetext{
Propriedades formais de estímulos verbais são as características apresentadas pelo estímulo verbal que determinam, em parte, o que ele parece ser ou o que ele indica para uma determinada comunidade verbal, de acordo com as suas práticas. Por exemplo, as regras: "você deve fazer o dever?", "você deve fazer o dever" e "você deveria fazer o dever", apresentam algumas características que permitem que uma determinada comunidade possa dizer que a primeira tem a forma de uma pergunta, a segunda tem a forma de uma ordem e a terceira tem a forma de uma sugestão (Albuquerque, Mescouto, \& Paracampo, 2011).
} 
comportamento e suas variáveis de controle; (b) a propriedade funcional de poderem evocar e determinar a topografia do comportamento e alterar probabilidade de esse comportamento vir a ocorrer e ser mantido independentemente das consequências imediatas produzidas pelo comportamento e independentemente de contiguidade espaço-temporal entre a regra e o comportamento e, (c) a propriedade funcional de poderem alterar a função de estímulos antecedentes e consequentes independentemente das consequências imediatas produzidas pelo comportamento e independentemente de contiguidade espaço-temporal entre a regra e o estímulo. É a propriedade formal de regras que permite que regras apresentem as suas duas propriedades funcionais e são essas três propriedades definidoras de regras que distinguem o ambiente verbal do ambiente não verbal.

Por essa proposição, regras são estímulos antecedentes verbais que podem descrever o comportamento e suas variáveis de controle; estabelecer a topografia do comportamento; alterar a probabilidade de esse comportamento vir a ocorrer e ser mantido; e, alterar as funções de estímulos, independentemente das consequências imediatas produzidas pelo comportamento e de contiguidade espaço-temporal entre estímulo-comportamento e estímulo-estímulo (Albuquerque et al., 2013). Comportamento é a ação do organismo como resultado de suas variáveis de controle (por exemplo, o seguimento de regra, o mando, o tacto, o intraverbal, o autoclítico, o pensamento, a auto-observação, o autoconhecimento, a consciência, o autocontrole). A ação do organismo como variável de controle do comportamento e o produto de tal ação constituem o ambiente social do organismo (por exemplo, os estímulos constituintes de contingências verbais e os estímulos constituintes de regras). O ambiente social verbal pode funcionar como regras e como contingências de reforço. Já o ambiente social não verbal pode funcionar como contingências de reforço, mas não funciona como regras. Desse modo, o ambiente social de humanos é verbal e o ambiente social de não humanos é não verbal. Portanto, é a propriedade definidora do ambiente verbal que permite que humanos, diferente de outros animais, possam ensinar e aprender o que conhecem por meio de regras, independentemente, tanto das consequências imediatas produzidas pelo comportamento, quanto de contiguidade espaço-temporal entre estímulos-comportamento e estímulos-estímulo, e, dessa forma, ampliem seus repertórios de comportamentos.

A definição de regras de Albuquerque et al. (2013) tem várias vantagens.

1. Essa definição identifica as propriedades definidoras de regras.

2. Ela unifica as principais definições de regras da área (Malott, 1989; Skinner, 1969; Schlinger \& Blakely, 1987; Zettle \& Hayes, 1982), mas, em adição à definição de Skinner, tal definição indica que regras podem alterar as funções de estímulos; em acréscimo à definição de Schlinger e Blakely, ela indica que regras podem evocar comportamento; também em acréscimo à definição de Malott, ela indica que regras podem determinar a topografia de comportamentos novos; em adição à definição de Zettle e Hayes, essa definição ainda indica que os efeitos de regras podem depender de suas propriedades formais; e, em acréscimo a todas as definições anteriores, ela enfatiza que regras podem exercer suas funções independentemente das consequências imediatas produzidas pelo comportamento e de contiguidade espaço-temporal entre estímulo-comportamento e estímulo-estímulo.

3. Além disso, a definição de regras de Albuquerque et al. (2013) indica a distinção entre ambiente verbal e não verbal e a distinção entre ambiente social de humanos e de não humanos. E,

4. Essa definição é apoiada em evidências experimentais (Albuquerque, de Souza, Matos, \& Paracampo, 2003; Albuquerque \& Ferreira, 2001; Albuquerque et al., 2011; Braga, Albuquerque, Paracampo, \& Santos, 2010; Matsuo, Albuquerque, \& Paracampo, 2014; Paracampo, Albuquerque, Mescouto, \& Farias, 2013). 


\section{Funções de Justificativas e de Consequências Imediatas}

A proposição de Albuquerque et al. (2013) de que regras podem alterar a probabilidade de $o$ comportamento por ela especificado vir a ocorrer e ser mantido, isto é, de que regras podem selecionar comportamento, deve ser esclarecida, uma vez que ela difere, em parte, da visão skinneriana de por que as pessoas se comportam da maneira como se comportam.

De acordo com Skinner (1974), todo o comportamento, incluindo o controlado por regras, é determinado por consequências. Por essa proposição, uma regra ("Faça exercícios físicos", por exemplo) pode evocar o comportamento por ela descrito, mas não alteraria a probabilidade de o seguimento de regra ocorrer no futuro, ou seja, uma regra não manteria o comportamento por ela evocado. Seriam as consequências que alterariam a probabilidade de esse comportamento vir a ocorrer e ser mantido. Em outras palavras, o que selecionaria se um ouvinte continuaria, ou não, seguindo a regra "Faça exercícios físicos", por exemplo, não seria a regra, mas a história de exposição às consequências para o seguimento de regras (Skinner, 1969). Os estudiosos da área concordam com essa proposição (Baum, 1999; Catania, 1998; Cerutti, 1989; Chase \& Danforth, 1991; Galizio, 1979; Hayes, Brownstein, Zettle, Rosenfarb, \& Korn, 1986; Newman, Buffington, \& Hemmes, 1995; Okoughi, 1999). Contudo, não fica claro nessa proposição de Skinner (1969) se as consequências que alterariam a probabilidade de o seguimento de regra ocorrer no futuro seriam as consequências imediatas produzidas pelo seguir e pelo não seguir regra ou as consequências futuras ${ }^{3}$ relatadas

Consequências imediatas são eventos produzidos imediatamente pelo comportamento após a sua emissão. Em um esquema de reforço de razão fixa, por exemplo, as consequências imediatas são a apresentação do reforço programado imediatamente após uma resposta (reforço) e a não a apresentação do reforço programado imediatamente após outras respostas (extinção). E consequências futuras são eventos que não são produzidos imediatamente pelo comportamento após a sua emis- em regras para a ocorrência e manutenção desses comportamentos.

A Teoria do Controle por Justificativas e por Consequências Imediatas (Teoria TJC) postula que a distinção entre os efeitos de estímulos constituintes de regras e os efeitos de outros estímulos na determinação do comportamento e das funções de estímulos é importante porque tal distinção implica em estabelecer os limites entre o que deve ser atribuído a funções de estímulos constituintes de regras e entre o que deve ser atribuído a funções de estímulos constituintes de contingências de reforço. Essa é uma questão nova e que não foi devidamente abordada por Skinner e tem sido abordada por poucos estudos na análise do comportamento (Albuquerque, Silva, \& Paracampo, 2014; Matsuo et al., 2014), apesar de sua importância para esclarecer o papel de estímulos constituintes de regras e de contingências de reforço na explicação do comportamento.

De acordo com a TJC, as consequências futuras relatadas em regras são estímulos antecedentes verbais constituintes da regra e podem exercer controle sobre o comportamento no momento em que o ouvinte entra em contato com a regra, isto é, quando a regra é ouvida e/ou lida pelo ouvinte. Já o evento futuro relatado, em si mesmo, não exerce controle sobre o comporta-

são e que podem ou não vir a ocorrer em longo prazo. Por exemplo, um comportamento (passear na Praça da República aos sábados de manhã) e uma consequência futura (encontrar a pessoa que procura) podem fazer parte de uma contingência de reforço. Mas quando um falante descreve essa relação para um ouvinte (quando o falante diz: "Passeie na Praça da República aos sábados de manhã que você encontrará a pessoa que procura") e o comportamento especificado por essa regra ocorre antes da ocorrência do evento relatado, tal comportamento deve ser considerado como controlado por regra com justificativa (os relatos de consequências futuras, em geral, são justificativas do Tipo 1). Quando o comportamento especificado pela regra produz o evento relatado, ele passa a ser controlado pela interação entre a justificativa do Tipo 1 (relato sobre onde encontrar a pessoa que procura) para o seguimento de regra e a consequência imediata produzida (contato com a pessoa encontrada; Paracampo et al., 2013). 
mento porque esse evento não é produzido pelo comportamento no momento em que o ouvinte entra em contato com a regra. Quando o evento relatado chega a ser produzido pelo comportamento, ele não é produzido como evento futuro, mas sim como uma consequência imediata do comportamento e é dessa forma que ele pode exercer controle. Desse modo, a regra funcionaria como substituto atual de eventos históricos e futuros por ela relatados (Albuquerque et al., 2011; Albuquerque et al., 2014; Paracampo et al., 2013).

A TJC também postula que uma regra, em geral, é contituída de estímulos que indicam o comportamento a ser evocado ("Tome isso", por exemplo). Mas regras também podem ser contituídas de estímulos que podem interferir na probabilidade de o comportamento por elas especificado vir a ocorrer e ser mantido ("Tome isso e você vai acabar morrendo" ou "Tome isso e você vai acabar melhorando", por exemplo; Albuquerque et al., 2013; Albuquerque et al., 2014). Albuquerque et al. (2013) denominaram de justificativas tais estímulos constituintes de regras. O termo justificativas foi empregado, principalmente, para distinguir os efeitos de estímulos constituintes de regras que podem selecionar comportamento (relato de consequências futuras, por exemplo) dos efeitos de outros estímulos (consequências imediatas do comportamento, por exemplo) na determinação do comportamento e das funções de estímulos. Justificativas, então, são estímulos constituintes de uma regra que podem alterar a função de estímulos, determinar a topografia do comportamento e a sua probabilidade de vir a ocorrer e ser mantido (Albuquerque et al., 2013). De acordo com esses autores, os principais tipos de justificativas são relatos antecedentes verbais a respeito de:

1. As eventuais consequências do seguimento ou do não seguimento de regras; observadas em relatos que podem indicar se as consequências são aversivas ou reforçadoras, de grande ou de pequena magnitude, passíveis de serem contatadas ou não. Por exemplo, um falante pode apresentar a regra: " $V a ́$ para X e não para $Y$ " e acrescentar a justificativa Tipo 1 "Porque em $X$ você terá tudo o que deseja".
2. A eventual aprovação ou desaprovação do seguimento ou do não seguimento de regra; observada em relatos que podem indicar se o falante ou outras pessoas fazem questão, ou não, que a regra seja seguida. Por exemplo, um falante pode dizer: "Estude", e acrescentar a seguinte justificativa do Tipo 2: "Não me decepcione".

3. A confiança do ouvinte no falante; expressa em relatos, tais como: "Não estou certo", "Eu garanto", "Quando fiz assim funcionou", "Pode confiar, ela tem bastante experiência", etc., que podem indicar se as consequências relatadas serão realmente produzidas, ou não, pelo seguimento ou pelo não seguimento de regra. Por exemplo, um falante pode apresentar a regra: "Invista seu capital em X" e acrescentar a seguinte justificativa do Tipo 3: "É um investimento seguro e rende bem, pode confiar, já estou no mercado há muito tempo".

4. A forma da regra, vista em relatos que podem indicar se a regra tem a forma de promessa, ordem, ameaça, acordo, discurso, aula, pergunta, filme, propaganda, poema, etc. Por exemplo, o falante pode dizer: "Não $v a$ " e acrescentar as seguintes justificativas do Tipo 4: "Eu imploro"; "Isso é uma ordem"; "Essa é a minha sugestão", etc. Em suma, as justificativas do Tipo 4 são as diferentes formas por meio das quais uma determinada justificativa pode ser apresentada ao ouvinte.

5. O que observar: relatos que podem indicar exemplos de comportamentos a serem seguidos e exemplos de comportamentos a não serem seguidos. Por exemplo, o falante pode dizer: "Coma toda a salada" e acrescentar a seguinte justificativa do Tipo 5: "Olhe como seu irmão já comeu tudo".

Deve ser destacado que, em geral, uma determinada justificativa, principalmente a do Tipo 4, é apresentada, não isoladamente, mas de forma combinada com outras justificativas. Também deve ser destacado que o ouvinte não é exposto a justificativas apenas quando está em contato com um falante específico. O ambiente verbal que pode afetar o comportamento do ouvinte (leitor) é constituído, em grande parte, de 
regras e de justificativas para o seguimento e para o não seguimento de regras disponibilizadas em vídeos, livros, aulas, palestras, documentos, leis, manuais, cartazes. Assim, o que há de comum em todos os exemplos já apresentados é que as justificativas são estímulos antecedentes verbais que podem alterar as funções de estímulos e interferir na manutenção do seguimento e do não seguimento de regras.

Há evidências experimentais que apoiam essa proposição. Por exemplo, Paracampo, Albuquerque, Carvalló e Torres (2009) avaliaram os efeitos de justificativas do Tipo 5 (relatos a respeito do que observar), apresentadas em histórias infantis, sobre o comportamento de seguir regra. Dez crianças, expostas a uma tarefa de doar bombons, foram distribuídas em dois grupos e cada grupo foi exposto a três fases. Os grupos diferiram quanto à história contada na Fase 2. Na Fase 2 do Grupo experimental, era contada uma história de um menino que tinha dificuldade de doar e dividir alimentos e, em decorrência disso, os seus amigos se afastam dele. No decorrer da história, o menino muda seu comportamento, passando a doar e dividir alimentos, por observar que outras crianças que apresentam esse comportamento têm amigos para brincar. A justificativa do Tipo 5 indicava, então, que dividir é legal, dividir é bom e quem divide e doa alimentos têm mais amigos para brincar. Na Fase 2 do Grupo controle, era lido um livro com características de animais. Nas Fases 1 e 3 dos dois grupos, era medido o número de bombons doados. Todos os cinco participantes do Grupo experimental fizeram doações na Fase 3. No Grupo controle, apenas 2 dos 5 participantes fizeram doações nessa fase. Tais diferenças de resultados entre os grupos, em conjunto com os resultados das Fases 1 e 3 do grupo experimental, mostrando que 2 dos 5 participantes desse grupo apresentaram um número maior de doações na Fase 3 do que na Fase 1, indicam que justificativas do Tipo 5 podem interferir na probabilidade de o seguimento de regra vir a ocorrer.

Já Braga et al. (2010) avaliaram os efeitos de justificativas dos Tipos 2 (relatos a respeito de eventual aprovação ou desaprovação do seguimento ou do não seguimento de regra) e 4 (relatos a respeito da forma da regra) sobre o seguimento de regras. Para tanto, 24 estudantes universitários foram expostos a um procedimento de escolha de acordo com o modelo, adaptado do desenvolvido por Albuquerque (1991). ${ }^{4} \mathrm{~A}$ ta-

4 Nesse procedimento, em cada tentativa era apresentado ao estudante um arranjo de estímulos, constituído de um estímulo modelo e três estímulos de comparação. Cada estímulo de comparação possuía apenas uma dimensão cor $(\mathrm{C})$, espessura (E) ou forma (F) em comum com o modelo e diferia nas demais. Na presença desses estímulos, o participante deveria apontar para os estímulos de comparação em uma dada sequência. O reforço programado era ponto trocado por dinheiro. As regras correspondente e discrepante continham a justificativa do Tipo 1 (relatos a respeito das eventuais consequências do seguimento ou do não seguimento de regras): "Fazendo isso, você poderá ganhar pontos, que serão mostrados no contador à sua frente", que indicava que o participante ganharia pontos trocáveis por dinheiro se seguisse a regra. A instrução ou pergunta era chamada de mínima por que não especificava qual sequência deveria ser emitida. A regra era chamada de correspondente quando a consequência imediata produzida pelo comportamento por ela especificado correspondia à justificativa do Tipo 1 constituinte da regra. Ou seja, quando o seguimento de regra produzia ponto. E a regra era chamada de discrepante quando a consequência imediata produzida pelo comportamento por ela especificado não correspondia à justificativa do Tipo 1 constituinte da regra. Isto é, quando o seguimento de regra não produzia ponto. Um critério para avaliar os efeitos de justificativas e de consequências imediatas sobre o comportamento é verificar se o comportamento ocorre sob o controle (isto é, se ocorre dependentemente), ou não (isto é, se ocorre independentemente), de suas consequências imediatas. $\mathrm{O}$ termo independência descreve o comportamento que não está sob o controle de suas consequências imediatas e o termo dependência descreve o comportamento que está sob o controle de suas consequências imediatas, em uma determinada situação particular. Assim, os efeitos de justificativas e de consequências imediatas sobre o comportamento podem ser testados experimentalmente pelo menos de duas maneiras: (a) mantendo inalteradas as contingências programadas no experimento e manipulando as regras com justificativas e, (b) mantendo inalteradas as regras com justificativas e manipulando as contingências programadas no experimento. Dessa forma, diz-se que o comportamento está sob o controle de justificativas quando 
refa era apontar para os estímulos de comparação em sequência. O participante era exposto a cinco fases. Na Fase 1 (linha de base) nenhuma sequência era instruída ou reforçada com ponto. Durante as Fases 2, 3, 4 e 5, constituída cada uma de duas sessões de 80 tentativas cada, as sequências corretas eram reforçadas em esquema de razão fixa 6 (FR 6). No início da Sessão 1 de cada fase, era apresentado um estímulo antecedente verbal, que podia ser uma instrução correspondente ou mínima, ou ainda uma pergunta correspondente ou mínima. A ordem em que esses estímulos eram apresentados era manipulada entre condições apenas para avaliar efeitos de ordem. Para avaliar se, na Sessão 1, o comportamento estava sob o controle do estímulo antecedente verbal ou de suas consequências imediatas programadas, tais consequências eram alteradas, sem sinalização, na Sessão 2. A instrução correspondente exerceu as funções de regras quando: (a) determinou a topografia do comportamento na Sessão 1 das fases em que foi apresentada e (b) manteve esse comportamento independentemente das consequências imediatas programadas na Sessão 2 dessas fases em 23 dos 24 casos possíveis (correspondente a 95\%). De modo similar, a pergunta correspondente também chegou a exercer essas funções de regras, mas isso ocorreu apenas em 8 dos 24 casos possíveis (correspondente a $33 \%$ ). Em contraste, apenas 2 dos 24 participantes responderam corretamente, tanto nas sessões iniciadas com a instrução mínima, quanto nas iniciadas com a pergunta mínima.

Tais diferenças de resultados, observadas entre condições, bem como entre fases de um mesmo participante, mostram que o comportamento especificado por regras tem maior probabilidade de ser selecionado (isto é, de ser estabelecido e mantido) por justificativa do Tipo 2 , após a mudança nas contingências programadas, quando essa justificativa indica que o experimen-

ele muda em função das mudanças nas justificativas, independentemente de suas consequências imediatas. E diz-se que o comportamento está sob o controle de consequências imediatas quando ele muda em função das mudanças nas contingências programadas independentemente de justificativas. tador aprova o seguimento de regra ("Quando eu mostrar estes objetos para você, você deve fazer o seguinte: Você deve apontar primeiro para a mesma cor, depois para a mesma espessura e em seguida para a mesma forma") do que quando a justificativa do Tipo 2 não indica claramente que o experimentador aprova o seguimento de regra, uma vez que ela questiona se o comportamento especificado pela regra é o que deve ser emitido ("Quando eu mostrar estes objetos para você, o que você deve fazer? Você deve apontar primeiro para a mesma cor, depois para a mesma espessura e em seguida para a mesma forma?").

Albuquerque et al. (2011) também avaliaram os efeitos de justificativas dos Tipos 2 (relatos a respeito de eventual aprovação ou desaprovação do seguimento ou do não seguimento de regra) e 4 (relatos a respeito da forma da regra) sobre o seguimento de regras. Para tanto, expuseram 24 estudantes universitários a um procedimento de escolha de acordo com o modelo, adaptado do desenvolvido por Albuquerque (1991). A tarefa era apontar para os estímulos de comparação em sequência. Os estudantes foram distribuídos em quatro grupos. Cada grupo era exposto a três fases. Na Fase 1, a sequência correta era estabelecida por reforço diferencial em CRF (esquema de reforço contínuo) e depois mantida em esquema FR 4. Nas Fases 2 e 3, as contingências de reforço programadas (as que estavam em vigor no final da Fase 1) eram mantidas inalteradas, enquanto eram manipuladas as justificativas para seguir regras discrepantes. Na Fase 1 dos Grupos 1 e 3 , eram feitas perguntas acerca das contingências programadas. Para os Grupos 2 e 4, não eram feitas perguntas. Para os Grupos 1 e 2, na Fase 2 era apresentada a justificativa do Tipo 2 em forma de sugestão: "Quando eu mostrar estes objetos para você, faça o que achar melhor para você. Se você quiser, você pode fazer o seguinte:..." e na Fase 3 era apresentada a justificativa do Tipo 2 em forma de ordem: "Quando eu mostrar estes objetos para você, eu quero que você faça o seguinte:...". Para os Grupos 3 e 4, era o inverso. No Grupo 1, cinco dos seis participantes não seguiram a sugestão na Fase 2. No Grupo 4, os cinco participantes seguiram a ordem na Fase 2. Nos Grupos 2 e 3 houve va- 
riabilidade nos resultados. Os resultados da Fase 2 dos Grupos 1 e 4, em conjunto, mostram que o comportamento especificado pela regra discrepante apresenta maior probabilidade de ser selecionado por justificativa do Tipo 2, quando essa justificativa indica que o experimentador faz questão que a regra seja seguida ("Quando eu mostrar estes objetos para você, eu quero que você faça o seguinte:..."), do que quando essa justificativa indica que o experimentador não faz claramente questão que a regra seja seguida ("Quando eu mostrar estes objetos para você, faça o que achar melhor para você. Se você quiser, você pode fazer o seguinte:...").

Matsuo et al. (2014, Experimento 2) investigaram os efeitos de justificativas dos Tipos 1 (relatos a respeito de eventuais consequências do seguimento ou do não seguimento de regras) e 2 (relatos a respeito de eventual aprovação ou desaprovação do seguimento ou do não seguimento de regra) sobre o seguimento de regras. Para tanto, seis estudantes universitários foram expostos a um procedimento de escolha de acordo com o modelo, adaptado do desenvolvido por Albuquerque (1991). A tarefa era escolher apontar para cada um dos três estímulos de comparação ou na sequência EFC (sequência simples) ou na sequência EFCFCE (sequência complexa). A regra sem justificativa adicional era do Tipo 1 e especificava a mesma promessa de concessão de pontos para a escolha tanto da sequência simples quanto da sequência complexa. A regra com justificativa adicional do Tipo 1 especificava que, se o participante escolhesse a sequência complexa, ele ganharia o dobro do que ganharia se escolhesse a sequência simples. A regra com justificativa adicional do Tipo 2 especificava que, se o participante escolhesse a sequência complexa, os demais participantes dessa pesquisa também ganhariam pontos e, dessa forma, ele estaria ajudando as outras pessoas. Nenhuma sequência produzia ponto. A Fase 1 (linha de base) era constituída de 10 tentativas onde nenhuma sequência era instruída ou reforçada. Cada uma das demais fases era iniciada com a apresentação de uma regra e encerrada após a ocorrência de 20 tentativas. Os seis participantes foram distribuídos em duas condições. Cada condição, rea- lizada com três participantes, era constituída de quatro fases. Nas duas condições, os participantes eram expostos à instrução mínima e à regra sem justificativa adicional do Tipo 1 , no início das Fases 1 e 2, respectivamente. As condições diferiam apenas quanto à ordem de apresentação das regras com justificativa adicional do Tipo 1 e do Tipo 2 nas Fases 3 e 4.

Os resultados mostraram que: (a) na ausência de instrução que especificasse sequências de respostas a serem apresentadas (caso da Fase 1), os participantes apresentaram um desempenho variável, emitindo diferentes sequências, e nenhum emitiu a sequência complexa; (b) nas fases em que a regra apresentava a mesma justificava do Tipo 1 (a obtenção de pontos) tanto para a escolha da sequência simples quanto para a escolha da sequência complexa (regra sem justificativa adicional), os participantes tenderam a apresentar a sequência simples; e, (c) nas fases em que a regra era com justificativa adicional do Tipo 1 (ganhar o dobro dos ganhos) ou com justificativa adicional do Tipo 2 (ajudar os outros) para a escolha da sequência complexa, os participantes tenderam a apresentar a sequência complexa. Tais resultados, mostrando que o comportamento mudou em função das mudanças nas justificativas entre fases de um mesmo participante, apoiam a proposição de que justificativas podem exercer as seguintes funções: (a) determinar a topografia do comportamento; (b) alterar a função de estímulos; e, (c) alterar a probabilidade de o comportamento vir a ocorrer e ser mantido. Desse modo, pode-se dizer que justificativas podem selecionar comportamento (Albuquerque et al., 2014; Matsuo et al., 2014).

Essa análise está de acordo com visão de que as consequências imediatas têm pouco efeito na determinação da topografia do comportamento previamente evocado por regras e que a topografia desse comportamento é determinada por variáveis sociais, introduzidas no ambiente do ouvinte, quando uma regra é apresentada (Albuquerque, 1991; Albuquerque et al., 2003; Baum, 1999; Cerutti, 1989; Catania, 1998; Malott, 1989; Skinner, 1969). De acordo com a TJC, tais variáveis seriam, por exemplo, os estímulos que constituem a regra que indicam: 
1. As consequências futuras para a emissão do comportamento especificado por regra e se o evento futuro relatado é reforçador ou é aversivo (justificativas do Tipo 1);

2. Se o falante faz questão, ou não, que a regra seja seguida (justificativas do Tipo 2); e,

3. Se o comportamento a ser emitido está ou não de acordo com práticas culturais (justificativas do Tipo 5). Os efeitos de tais justificativas, no entanto, ao invés de serem considerados efeitos de estímulos antecedentes verbais (isto é, de estímulos constituintes de regras), têm sido considerados como se fossem efeitos de consequências imediatas (isto é, de contingências de reforço), ou mais especificamente, como se fossem efeitos de: contingências verbais (Skinner, 1969); consequências mediadas socialmente (Zettle \& Hayes, 1982); consequências instrucionais (Cerutti, 1989), contingências que agem direta e indiretamente (Malott, 1989), contingência próxima e contingência última (Baum, 1999); contingências verbais e sociais de ordem superior (Catania, 1998) e consequências culturais (Matos, 2001). Contudo, o uso de tais termos, bem como a classificação do seguimento de regras em Pliance (aquiescência) e Tracking (rastreamento; Hayes, Brownstein, Zettle, et al., 1986), não contribui para o esclarecimento da distinção entre o que é controle por tipos de justificativas (Tipos 1, 2, 3, 4 e 5) e o que é controle por tipos de consequências imediatas (reforço positivo, reforço negativo, extinção e punição) e, dessa maneira, não contribui para distinguir o que é controle por estímulos constituintes de regras e o que é controle por estímulos constituintes de contingências de reforço (Albuquerque et al., 2014).

A TJC postula, com base nos resultados dos estudos de Albuquerque et al. (2011) e Braga et al. (2010), que o comportamento pode ser mantido por aprovação indicada por justificativas e não apenas por consequências imediatas. A diferença é que, na aprovação ou desaprovação por justificativas, os estímulos (como críticas, elogios, indicações de comportamento considerado correto ou incorreto, de admiração, de rejeição) são antecedentes e, portanto, apresentados antes da ocorrência do comportamento a ser mantido. Por exemplo, após a regra: "Fique", é acrescentada a justificativa do Tipo 2 (relatos a respeito da eventual aprovação ou desaprovação do seguimento ou do não seguimento de regra): " $E u$ vou ficar muito feliz se você ficar". Já na aprovação ou desaprovação por consequências imediatas, os estímulos (como críticas, elogios, indicações de comportamento considerado correto ou incorreto, de admiração, de rejeição) são consequentes e, portanto, apresentados após a ocorrência do comportamento. Por exemplo, após o ouvinte ficar, é apresentada a seguinte consequência imediata: "Fiquei muito feliz por você ter ficado". Nos dois casos, o comportamento de ficar poderia ser mantido, mas a seleção desse comportamento pela aprovação deveria ser atribuída a efeitos de justificativas (como estímulos constituintes de regras) no primeiro caso, e a efeitos de consequências imediatas (como estímulos constituintes de contingências de reforço) no segundo caso.

Outra distinção postulada pela TJC é entre estímulo verbal que pode funcionar como consequência imediata para um comportamento que ocorreu e, ao mesmo tempo, como justificativa para um comportamento futuro, dependendo em parte de suas propriedades formais. Por exemplo, um comentário (consequência verbal apresentada imediatamente após um comportamento) pode funcionar como uma crítica (diminuindo a probabilidade de o comportamento criticado voltar a ocorrer) ou como um elogio (aumentando a probabilidade de o comportamento elogiado voltar a ocorrer) dependendo, em parte, de suas propriedades formais. Geralmente, o comentário pode funcionar como consequência imediata para um comportamento que ocorreu e como regra com justificativa para um comportamento futuro, quando, entre as suas propriedades formais, ele apresenta também a forma de sugestões, recomendações, avisos, advertências, ameaças, promessas.

Como distinções como essas, em geral, não têm sido feitas, algumas afirmações sobre a contribuição de estímulos constituintes de regras e 
de estímulos constituintes de contingências de reforço não ficam claras. Desse modo, quando Skinner (1974) sugere que todo comportamento é determinado, direta ou indiretamente, pelas consequências, não fica clara se a fonte de controle dessa afirmação são as consequências imediatas (como estímulos constituintes de contingências de reforço) ou as justificativas (como estímulos constituintes de regras), diferenciais para seguir e para não seguir regras (Albuquerque et al., 2014).

\section{Histórias do Ouvinte}

$\mathrm{Na}$ área que investiga as funções de regras, os autores, de modo geral, concordam que o seguimento de regras seria mantido devido a uma história de "reforço" social para o seguimento e de "punição" social para o não seguimento de regra (Baum, 1999; Baron \& Galizio, 1983; Catania, 1998; Cerutti, 1989; Chase \& Danforth, 1991; Okoughi, 1999; Mallot, 1989; Skinner, 1969, 1974; Wulfert, Greenway, Farkas, Hayes, \& Dougher, 1994; Zettle \& Hayes, 1982). No entanto, não fica claro nessa afirmação, se o que é considerado como efeitos de reforço ou punição social, deveria, ou não, ser considerado como efeitos de justificativas (como estímulos antecedentes constituintes de regras) ou como efeitos de consequências imediatas (como estímulos consequentes constituintes de contingências de reforço). Isso não fica claro, porque nesses estudos essa distinção não é considerada, uma vez que as variáveis nela envolvidas (as justificativas para o seguimento de regras e as consequências imediatas produzidas por esse comportamento) são todas tratadas da mesma forma, indistintamente, como integrantes de uma mesma categoria conceitual "estímulos consequentes" que manteria o comportamento evocado por regras. Por exemplo, a afirmação de Skinner (1969) que sugere que de algum modo regras precisam prometer ou ameaçar consequências para poderem ser seguidas, não considera a distinção em exame no presente estudo. De acordo com a TJC, promessas e ameaças de consequências são justificativas, isto é, são variáveis incluídas na categoria conceitual "estímulos antecedentes". Já os eventos relatados por tais justificativas, apenas quando contatados pelo comportamento, são as consequências imediatas do comportamento (reforço positivo, reforço negativo, punição, extinção), ou seja, são variáveis incluídas na categoria conceitual "estímulos consequentes".

Considerando isso, a TJC postula que o comportamento de seguir regras pode ocorrer, não somente devido a uma história de controle por consequências imediatas diferenciais, mas também pode ocorrer devido a uma história de controle por justificativas diferenciais e devido a uma história de controle pela interação entre justificativas e consequências imediatas diferenciais, para seguir e para não seguir regra. A diferença entre essas três histórias é que, na história de controle por consequências imediatas diferenciais, o comportamento especificado pela regra é colocado sob o controle da regra por suas consequências imediatas diferenciais e não por justificativas. Já na história de controle por justificativas diferenciais, o comportamento especificado pela regra é colocado sob o controle da regra por justificativas diferenciais e não por consequências imediatas. E na história de controle pela interação entre justificativas e consequências imediatas diferenciais, o seguimento de regra é mantido pela interação entre essas variáveis. A distinção entre essas três histórias pode ficar mais clara quando são analisadas as condições sob as quais justificativas e eventos futuros relatados em justificativas podem, ou não, exercer suas funções.

As regras podem ser com justificativas $e$ sem justificativas. Quando a regra é sem justificativas (a regra: "Fique", por exemplo), o comportamento por ela especificado não é afetado por justificativa relatada na regra. Quando o ouvinte só passa a seguir essa regra porque no passado o seguimento de regra (a apresentação do comportamento de ficar) foi reforçado (com elogio, por exemplo) e o não seguimento de regra (a apresentação do comportamento de não ficar) foi punido (com repreensão, por exemplo), o seguimento dessa regra passa a ser mantido, em parte, sob o controle de suas consequências imediatas. Condições como essa poderiam passar a fazer parte da história do ouvinte de controle por con- 
sequências imediatas diferenciais para seguir e para não seguir regras.

Quando a regra é com justificativas (a regra: "Fique que vou aumentar o seu salário", por exemplo), o comportamento por ela especificado (Ficar) pode ser afetado pela justificativa relatada na regra ("Vou aumentar o seu salário"). Quando o comportamento de seguir essa regra produz o evento relatado (o ouvinte recebe o salário com aumento), o seguimento da regra passa a ser mantido, em parte, pela interação entre justificativas e consequências imediatas. Condições como essa poderiam passar a fazer parte da história do ouvinte de controle pela interação entre justificativas diferenciais e consequências imediatas diferenciais para seguir e para não seguir regra.

As justificativas podem relatar eventos futuros passiveis e eventos futuros não passiveis de serem contatados (produzidos) pelo comportamento de seguir e pelo comportamento de não seguir regra. Um exemplo do primeiro caso seria uma justificativa do Tipo 1 (relatos a respeito de eventuais consequências do seguimento ou do não seguimento de regras) que indica que a manutenção do seguimento de uma regra para fazer serviços diários em uma loja produzirá um salário por mês. Um exemplo do segundo caso seria uma justificativa do Tipo 5 (relatos a respeito do que observar) que indica que a manutenção do seguimento de uma regra para fazer doações mensais a uma instituição produzirá a bênção de Deus (nesse caso, a justificativa do Tipo 5 poderia ser: "As pessoas que costumam fazer coisas que mostram que elas são de fato pessoas boas, como fazer doações, têm a bênção de Deus"). Nos dois casos, as justificativas, como estímulos antecedentes verbais constituintes de regras, exercem controle no momento em que a regra é apresentada, após o ouvinte entrar em contato com a regra, isto é, após o ouvinte ler e/ou ouvir a regra. Já o evento futuro relatado na justificativa (o salário no primeiro caso e a bênção de Deus no segundo caso), como evento futuro, não exerce controle porque esse evento não é produzido pelo comportamento especificado pela regra no momento em que a regra é apresentada.
No primeiro caso, quando o evento relatado chega a ser produzido pelo comportamento previamente especificado pela regra, ele não é produzido como evento futuro, mas sim como uma consequência imediata do comportamento e é dessa forma que ele pode exercer controle. Desse modo, no primeiro caso, quando o comportamento especificado pela regra, sob o controle prévio de justificativa do Tipo 1 , produz o evento relatado (o ouvinte recebe o salário), ele (o seguimento de regra) passa a ser controlado pela interação entre a justificativa e a consequência imediata produzida. Condições como essa poderiam passar a fazer parte da história do ouvinte de controle pela interação entre justificativas diferenciais e consequências imediatas diferenciais para seguir e para não seguir regra

Já no segundo caso, como o evento relatado (a bênção de Deus) não pode ser produzido pelo seguimento de regra, esse comportamento ficaria sob o controle da justificativa do Tipo 5 (relatos a respeito do que observar). Desse modo, diferente de quando as regras são sem justificativas, quando regras são com justificativas, tais justificativas podem selecionar o comportamento, ou seja, podem estabelecer e manter o comportamento especificado pela regra. Condições como essa poderiam passar a fazer parte da história do ouvinte de controle por justificativas diferenciais para seguir e para não seguir regras.

Além das justificativas que podem relatar eventos futuros passíveis e não passíveis de serem produzidos pelo seguimento e pelo não seguimento de regra, há também justificativas que podem relatar eventos futuros que não são claramente produzidos pelo comportamento de seguir e de não seguir regra. Por exemplo, uma pessoa pode seguir uma regra com a justificativa do Tipo 1 (relatos a respeito de eventuais consequências do seguimento ou do não seguimento de regras) de que fazendo o que a regra especifica para ser feito produzirá sentimento de segurança, liberdade, felicidade, etc. Uma pessoa também pode seguir uma regra com a justificativa do Tipo 2 (relatos a respeito de eventual aprovação ou desaprovação do seguimento ou do não seguimento de regra) de que o seguimento de regra produzirá aprovação ou a admiração do 
grupo, mesmo não produzindo tais eventos relatados. Nesse caso, quando o seguimento de regra produz o evento relatado (o ouvinte recebe um elogio, por exemplo), ele passa a ser controlado pela interação entre justificativas e consequências imediatas. Condições como essa poderiam passar a fazer parte da história do ouvinte de controle pela interação entre justificativas diferenciais e consequências imediatas diferenciais para seguir e para não seguir regra.

É possível, no entanto, que ouvinte possa notar que o seguimento de regras, quando apresentado, não por ele (ouvinte), mas por outras pessoas, pode chegar a manter contato com qualquer evento futuro relatado. Isso pode ocorrer quando os exemplos de comportamentos que deveriam ser seguidos, ou não, indicados ao ouvinte por justificativas do Tipo 5 (relatos a respeito do que observar), são comportamentos apresentados por personagens de contos, histórias infantis, romances, novelas, filmes, etc. Em geral, os autores constroem personagens que relatam as justificativas pelas quais fazem o que fazem e costumam contatar os eventos futuros relatados pelas justificativas. Dessa forma, os personagens relatam que fazem o que fazem por medo, dinheiro, sexo, amor, ódio, em busca de bem estar, beleza, segurança, felicidade, liberdade, da realização de um sonho, em defesa ou contra uma causa, ou um modo de pensar, etc. Assim, por agir de acordo com o que os seus criadores consideram correto, incorreto ou indiferente, alguns personagens podem contatar eventos relatados, tais como: morrer por uma causa, viver como herói no pensamento das pessoas, ou no inferno, como alma perdida, por exemplo. Tais relatos, em sua maior parte, são justificativas do Tipo 5 (relatos a respeito do que observar) que podem indicar para o ouvinte os exemplos de comportamentos e os exemplos de eventos e objetos relatados que os diferentes grupos valorizam, aprovam, consideram corretos, legais, éticos, morais, tolerados, indiferentes, ou não. Similarmente, aulas, palestras, sermões, reportagens, documentários e discursos, também, em sua maior parte, funcionam como justificativas do Tipo 5. Por exemplo, em uma aula, um professor pode apresentar justificativas para o ouvinte pensar como Skinner e não como Rogers. Desse modo, a história específica de controle por justificativas do Tipo 5 teria duas principais funções: (a) permitir que o ouvinte aprenda com os relatos das histórias dos outros, isto é, que o ouvinte aprenda com justificativas contidas nos relatos das histórias de outras pessoas ou de personagens de livros, filmes, novelas e, (b) contribuir para a manutenção tanto do comportamento de seguir quanto do comportamento de não seguir regras, na medida em que pode indicar por que certos exemplos de regras devem ser seguidos e por que outros exemplos de regras não devem ser seguidos por determinadas comunidades em determinadas situações. Condições como essas poderiam passar a fazer parte da história mais geral do ouvinte de controle por justificativas diferenciais para seguir e para não seguir regras.

Outra história especial é a história específica do comportamento alternativo ao descrito pela regra discrepante, isto é, comportamento que substitui o comportamento especificado pela regra discrepante. Por exemplo, pacientes com diabetes em geral são expostos a regras do tratamento com justificativas para o seu seguimento. O seguimento de tais regras, no entanto, não produz imediatamente os eventos futuros relatados nas justificativas (controle do peso, estética do corpo, controle da glicemia, saúde, bem-estar), o que faz dessas regras serem discrepantes. Além disso, tais pacientes, em geral, têm histórias de controle por consequências imediatas diferenciais e de controle por justificativas diferenciais para a manutenção de comportamentos alternativos aos comportamentos especificados pelas regras do tratamento (isto é, têm uma história com estilo de vida sedentária e de comer alimentos pouco saudáveis). As regras do tratamento serão seguidas, ou não, dependendo, em parte, das relações entre as variáveis combinadas que favorecem e que não favorecem a manutenção do comportamento por elas especificado e as variáveis combinadas que favorecem e que não favorecem a manutenção do comportamento alternativo em exame (o estilo de vida sedentária 
e de comer alimentos pouco saudáveis). Quando o seguimento das regras do tratamento passa a produzir os eventos relatados nas justificativas, tais regras tornam-se correspondentes (Albuquerque et al., 2013; Albuquerque et al., 2014; Najjar, Albuquerque, Ferreira, \& Paracampo, 2014). Condições como essas poderiam passar a fazer parte da história mais geral do ouvinte de controle pela interação entre justificativas diferenciais e consequências imediatas diferenciais para seguir e para não seguir regra.

A TJC postula, então, que histórias de seguimento de regras são constituídas, não apenas de contatos com consequências imediatas passadas, mas também de contatos com justificativas passadas que relatam eventos futuros, e que a sua principal função seria contribuir para a ocorrência e manutenção do comportamento, tanto o de seguir quanto o de não seguir regras, de acordo com práticas culturais às quais o ouvinte é exposto. Mas isso não implica que as pessoas seguiriam qualquer regra, indiscriminadamente, apenas porque têm uma história de seguimento de regras (Albuquerque et al., 2011). Os resultados do estudo de Albuquerque et al. (2011) mostram que o seguimento de uma ou outra regra também depende de justificativas atuais para seguir ("eu quero que você faça o seguinte:...") e para seguir ou não seguir regras ("faça o que achar melhor para você. Se você quiser, você pode fazer o seguinte:...") e de outras variáveis ambientais atuais, como as consequências imediatas produzidas pelo seguir e pelo não seguir regras.

\section{Comparações entre Estímulos Constituintes de Regras e de Contingências de Reforço}

Tem sido sugerido que o comportamento está sob o controle de regra quando ele é estabelecido por regra (Hayes, Brownstein, Haas, \& Greenway, 1986). De acordo com a TJC, entretanto, nem todo comportamento que se segue à apresentação de uma regra particular pode ser classificado como controlado pela regra. Para que um comportamento seja considerado como controlado por regras é necessário descartar a possibilidade de que ele esteja sob o controle de suas consequências imediatas. Similarmente, para que um comportamento seja considerado como controlado por contingências de reforço é necessário descartar a possibilidade de que ele esteja sob o controle de regras, sejam essas regras apresentadas pelo falante ao ouvinte, sejam formuladas pelo próprio ouvinte (Albuquerque, Reis, \& Paracampo, 2006). Assim, o comportamento é controlado por regras quando ele é estabelecido por regra e ocorre independentemente de suas consequências imediatas (caso, por exemplo, dos participantes do Grupo 4 do estudo de Albuquerque et al., 2011, que seguiram a regra discrepante independentemente de suas consequências imediatas na Fase 2). E o comportamento é controlado por contingências de reforço, quando ele é estabelecido por suas consequências imediatas e ocorre independentemente de regras (caso do único participante que abandonou o seguimento da regra correspondente e passou a apresentar um comportamento estabelecido e mantido por suas consequências imediatas, quando as contingências programadas foram alteradas, no estudo de Braga et al., 2010, por exemplo). Isso não implica que o comportamento especificado por uma regra não possa ser afetado por suas consequências imediatas. $\mathrm{O}$ seguimento de regra pode ser afetado por suas consequências imediatas. No entanto, quando isso ocorre, esse comportamento deixa de ser controlado por regra e passa a ser ou controlado pelas contingências de reforço ou controlado pela interação entre regra e contingências de reforço. O comportamento é controlado pela interação entre regra e contingência de reforço quando ele é mantido, em parte, pela interação entre justificativas constituintes de regra e consequências imediatas (Albuquerque et al., 2003; Albuquerque \& Paracampo, 2010; Albuquerque et al., 2011; Albuquerque et al., 2014; Braga et al., 2010).

Ainda de acordo com a TJC, quando o comportamento é controlado por regras, são as justificativas que determinam a topografia do comportamento; a probabilidade de o comportamento vir a ocorrer e ser mantido; e, alteram as funções dos estímulos. Já quando o compor- 
tamento é controlado por contingências de reforço, são as consequências imediatas do comportamento que exercem essas funções. Mas diferente de tais contingências, regras com justificativas podem estabelecer um comportamento novo independentemente de suas consequências imediatas. Desse modo, tais regras não deveriam ser chamadas de "contingências verbais". O termo contingências de reforço, sejam elas verbais ou não verbais, enfatiza os efeitos de consequências imediatas; enquanto que o termo regras enfatiza os efeitos de estímulos antecedentes verbais, na determinação da topografia do comportamento. Assim, o termo "contingências verbais" deveria ser usado para descrever o comportamento do ouvinte que é estabelecido por consequências imediatas verbais, tais como elogios, críticas, etc.; mas não deveria ser usado para descrever o comportamento do ouvinte que é estabelecido por regra e mantido por justificativas constituintes de regras. O termo "regras" também não deveria ser substituído pela palavra "verbalmente" (Vargas, 1988), porque não está claro se a palavra "verbalmente" se refere a um comportamento, a uma consequência imediata ou a um estímulo antecedente. Dessa forma, o termo "verbalmente" não contribui para o esclarecimento da distinção, em exame no presente estudo, entre como estímulos antecedentes verbais e estímulos consequentes verbais e não verbais selecionam o comportamento.

Portanto, regras com justificativas podem exercer múltiplas funções e quando essa característica é desconsiderada, ou seja, quando elas são definidas com base apenas em uma de suas múltiplas funções (por exemplo, quando elas são definidas apenas como estímulo discriminativo), a definição de regras torna-se muito limitada (Albuquerque, 2001, 2005; Albuquerque et al., 2011; Albuquerque \& Paracampo 2010). Considerando isso, regras com justificativas não deveriam ser classificadas apenas como estímulos alteradores de função (Schlinger \& Blakely, 1987), porque elas também podem evocar comportamento (Albuquerque, 2001). Tais regras também não deveriam ser classificadas apenas como estímulos discriminativos (Cerutti, 1989; Galizio, 1979; Okoughi, 1999; Skinner, 1969), nem como operações estabelecedoras (Malott, 1989), porque, diferente de regras com justificativas, estímulos discriminativos e operações estabelecedoras não determinam a topografia do comportamento (Albuquerque, 2001; Albuquerque \& Paracampo, 2010).

A distinção entre justificativas, consequências imediatas verbais, mando e autoclítico também é importante, porque essas variáveis podem apresentar algumas propriedades formais similares. De acordo com a TJC, justificativas e consequências imediatas são variáveis de controle do comportamento, tanto do comportamento verbal quanto do não verbal. Em outras palavras, são variáveis independentes que podem estabelecer e manter o comportamento e alterar a função de estímulos, isto é, que podem selecionar comportamento. A diferença é que justificativas são estímulos antecedentes verbais, constituintes de regras, e podem exercer suas funções independentemente de consequências imediatas, enquanto que consequências imediatas são estímulos consequentes, constituintes de contingências de reforço, que podem ser tanto verbais quanto não verbais.

Diferente de justificativas e de consequências imediatas, o mando e o autoclítico são comportamentos verbais, isto é, são variáveis dependentes. De acordo com Skinner (1957), o "mando" é um operante verbal no qual a resposta é reforçada por uma consequência característica e está sob o controle funcional de condições relevantes de privação ou estímulo aversivo; e, o termo "autoclítico" sugere um comportamento que se fundamenta em (ou que depende de) outro comportamento verbal. As consequências especiais que mantém o comportamento autoclítico são as respostas práticas do ouvinte que dependem de uma correspondência entre o comportamento verbal e um estado de coisas estimulador. Dito de outro modo, o comportamento autoclítico produz uma "ação apropriada no ouvinte". Essa "ação apropriada do ouvinte" consiste em reforçar ou mediar o reforço do comportamento do falante.

O efeito das respostas classificadas como mando sobre o ouvinte é o de produzir o reforço especificado. Já o efeito das respostas classifi- 
cadas como autoclíticas sobre o ouvinte é o de produzir o reforço apropriado. Nos dois casos, a ação do ouvinte, como consequência produzida pelo comportamento do falante, é a de funcionar como auditório, a de reforçar (ou punir) e/ou a de mediar o reforço do comportamento do falante, seja ele mando ou autoclítico. Após serem realizadas, as ações classificadas como mando e autoclítico tornam-se estímulos verbais. Tais estímulos podem fazer parte integrante de justificativas (quando são estímulos antecedentes) ou de consequências imediatas verbais (quando são estímulos consequentes). Portanto, diferente do mando, do autoclítico e das consequências imediatas verbais, justificativas são definidas por serem estímulos antecedentes verbais constituintes de regras e por poderem exercer a função de selecionar comportamento independentemente das consequências imediatas produzidas pelo comportamento e de contiguidade espaço-temporal entre estímulo-comportamento e estímulo-estímulo.

Dessa forma, a TJC postula que o mando e o autoclítico, bem como qualquer comportamento verbal, também podem ser selecionados por justificativas. De acordo com a TJC, o auditório e o reforço generalizado também podem ter suas funções estabelecidas por justificativas. A promessa de reforço e a ameaça de punição, geralmente utilizadas pela comunidade verbal para estabelecer e manter o comportamento verbal, funcionam como justificativas que relatam eventos futuros passíveis e não passíveis de serem contatados. As justificativas do Tipo 5 (relatos a respeito do que observar), podem exemplificar (em livros, filmes, internet, conversas, etc.) quais as características que um dado comportamento verbal (falado ou escrito) deve apresentar em determinado auditório (cientifico, literário, etc.); ou quais auditórios específicos (profissionais, amigos, parentes, estranhos) são mais ou menos punitivos para certos assuntos, etc. Portanto, uma comunidade verbal não é constituída apenas das práticas de reforço de respostas, isto é, das condições sob as quais uma resposta é caracteristicamente por ela reforçada, mas também é constituída das condições sob as quais uma resposta é regularmente mantida por justificativas.
Portanto, a TJC amplia as possibilidades de análise do comportamento. Outra vantagem da TJC é que ela é passível de ser testada, uma vez tanto justificativas quanto consequências imediatas podem ser manipuladas e seus efeitos podem ser observados e registrados. Desse modo, pesquisas futuras poderiam comparar os efeitos dessas duas variáveis de controle na determinação da manutenção do comportamento verbal, tanto em situações práticas como em laboratório.

\section{Considerações Finais}

De acordo com Skinner (1981, 1989), os amplos repertórios de comportamentos das pessoas seriam selecionados por consequências sociais para a sobrevivência do grupo. Tais consequências selecionariam as práticas culturais (isto é, as maneiras que os indivíduos da mesma espécie ajudariam uns aos outros) mais bem sucedidas na solução de problemas e, dessa forma, poderiam contribuir para a sobrevivência do grupo praticante. Mas tais consequências não reforçariam o comportamento de seus membros, uma vez que elas não seriam imediatas o bastante para exercerem essa função. Skinner $(1981,1989)$, no entanto, não deixa claro como tais "consequências futuras" selecionariam os amplos repertórios de comportamentos dos humanos (Albuquerque, 2005; Albuquerque et al. 2014).

Diferente dessa proposição de Skinner, a TJC postula que os amplos repertórios de comportamentos dos humanos também podem ser selecionados por justificativas. Os resultados dos estudos de Albuquerque et al. (2011); Braga et al. (2010); Matsuo, et al. (2013) e Paracampo et al. (2009), mostrando que justificativas podem: (a) alterar a função de estímulos; (b) determinar a topografia do comportamento; e, (c) alterar a probabilidade de o comportamento vir a ocorrer e ser mantido, apoiam essa conclusão. Por essa teoria, justificativas (como componentes de uma regra), podem exercer funções muito similares às exercidas pelas consequências imediatas do comportamento (como um componente de uma contingência de reforço). A diferença é que justificativas podem exercer essas funções como substitutos atuais de eventos históricos e futuros. 
Além das evidências experimentais, também há evidências práticas que apoiam a proposição de que justificativas podem selecionar comportamento. Um exemplo do cotidiano das pessoas de que justificativas podem exercer a função de selecionar comportamento, pode ser encontrado quando se considera que a prática cultural de usar camisinha em relações sexuais foi selecionada e está sendo mantida, em grande parte, por justificativas: do Tipo 1 (relatos a respeito das eventuais consequências do seguimento ou do não seguimento de regras), como relatos que recomendam o uso de camisinha para evitar doenças sexualmente transmissíveis; do Tipo 2 (relatos a respeito da eventual aprovação ou desaprovação do seguimento ou do não seguimento de regra), como relatos de autoridades, pessoas famosas, cientistas recomendando o uso de camisinha; do Tipo 3 (relatos a respeito da confiança do ouvinte no falante), como relatos que indicam que, sem camisinha, não há sexo seguro, mesmo em relações estáveis; do Tipo 4 (relatos a respeito da forma da regra), como a apresentação de tais justificativas na forma de manual, propaganda, aulas, palestras, etc.; e, do Tipo 5 (relatos a respeito do que observar: relatos que podem indicar exemplos de comportamentos a serem seguidos e exemplos de comportamentos a não serem seguidos), como relatos a respeito de pessoas que não seguiram a regra e contraíram uma doença grave ou morreram; a exibição de fotos e/ou cenas em que aparece os sintomas da doença contraída; o sofrimento da pessoa doente, etc.

Em suma, pela TJC, o comportamento de não humanos é selecionado por suas consequências imediatas. Diferentemente, o comportamento humano, além de poder ser selecionado por tais consequências, também pode ser selecionado por justificativas. Dessa forma, a aprendizagem por justificativas envolve um processo novo, diferente do envolvido na aprendizagem por consequências imediatas. Diferente da aprendizagem por consequências imediatas, na aprendizagem por justificativas, a contiguidade espaço-temporal entre estímulo e resposta não é uma variável crítica.
Uma importância prática dessa distinção é que os profissionais e pesquisadores deveriam passar a notar que quando se diz que o que se manipula são as consequências do comportamento, na realidade o que de fato frequentemente se manipula, principalmente na clínica, são os relatos antecedentes de tais consequências, isto é, as justificativas do Tipo 1 (relatos a respeito das eventuais consequências do seguimento ou do não seguimento de regras).

\section{Referências}

Albuquerque, L. C. (1991). Efeitos de regras no controle do comportamento humano [Resumo]. In Sociedade Brasileira de Psicologia (Ed.), Resumos de comunicações cientificas. XXI Reunião Anual de Psicologia (p. 162). Ribeirão Preto, SP: Sociedade Brasileira de Psicologia.

Albuquerque, L. C. (2001). Definições de regras. In H. J. Guilhardi, M. B. B. P., Madi, P. P., Queiroz, P. P., \& M. C. Scoz (Eds.), Sobre comportamento e cognição: Expondo a variabilidade (pp. 132-140). Santo André, SP: ARBytes.

Albuquerque, L. C. (2005). Regras como instrumento de análise do comportamento. In L. C. Albuquerque (Ed.), Estudos do comportamento (pp. 143-176). Belém, PA: Editora da Universidade Federal do Pará.

Albuquerque, L. C., \& Ferreira, K. V. D. (2001). Efeitos de regras com diferentes extensões sobre o comportamento humano. Psicologia: Reflexão e Crítica, 14, 143-155.

Albuquerque, L. C., \& Paracampo, C. C. P. (2010). Análise do controle por regras. Psicologia USP, 21, 253-273. doi:http://dx.doi.org/10.1590/ S0103-65642010000200004

Albuquerque, L. C., de Souza, D. G., Matos, M. A., \& Paracampo, C. C. P. (2003). Análise dos efeitos de histórias experimentais sobre o seguimento subsequente de regras. Acta Comportamentalia, $11,87-126$

Albuquerque, L. C., Mescouto, W. A., \& Paracampo, C. C. P. (2011). Controle por regras: Efeitos de perguntas, sugestões e ordens. Acta Comportamentalia, 19, 19-42.

Albuquerque, L. C., Paracampo, C. C. P., Matsuo, G. L., \& Mescouto, W. A. (2013). Variáveis combinadas, comportamento governado por regras 
e comportamento modelado por contingência. Acta Comportamentalia, 21, 285-304.

Albuquerque, L. C., Reis, A. A., \& Paracampo, C. C. P. (2006). Efeitos de uma história de reforço contínuo sobre o seguimento de regra. Acta Comportamentalia, 14, 47-75.

Albuquerque, L. C., Silva, L. S., \& Paracampo, C. C. P. (2014). Análise de variáveis que podem interferir no comportamento de seguir regras discrepantes. Acta Comportamentalia, 22, 51-71.

Baron, A., \& Galizio, M. (1983). Instructional control of human operant behavior. The Psychological Record, 33, 495-520.

Baum, W. M. (1999). Compreender o behaviorismo: ciência, comportamento e cultura. Porto Alegre, RS: Artmed (Original publicado em 1994)

Braga, M. V. N., Albuquerque, L. C., Paracampo, C. C. P., \& Santos, J. V. (2010). Efeitos de manipulações de propriedades formais de estímulos verbais sobre o comportamento. Psicologia: Teoria e Pesquisa, 4, 129-142. doi:http://dx.doi. org/10.1590/S0102-37722010000400010

Catania, A. C. (1998). Learning. Hillsdale, NJ: Prentice Hall.

Cerutti, D. T. (1989). Discrimination theory of rulegoverned behavior. Journal of the Experimental Analysis of Behavior, 51, 259-276. doi:10.1901/ jeab.1989.51-259

Chase, P. N., \& Danforth, J. S. (1991). The role of rules in concept learning. In L. J. Hayes \& P. N. Chase (Eds.), Dialogues on verbal behavior (pp. 205-225). Hillsdale, NJ: Lawrence Erlbaum.

Galizio, M. (1979). Contingency-shaped and rulegoverned behavior: Instructional control of human loss avoidance. Journal of the Experimental Analysis of Behavior, 31, 53-70.

Hayes, S. C., Brownstein, A. J., Haas, J. R., \& Greenway, D. (1986). Instructions, multiple schedules, and extinction: Distinguishing rule-governed from schedule-controlled behavior. Journal of the Experimental Analysis of Behavior, 46, 137147. doi:10.1901/jeab.1986.46-137

Hayes, S. C., Brownstein, A. J., Zettle, R. D., Rosenfarb, I., \& Korn, Z. (1986). Rule governed behavior and sensitivity to changing consequences of responding. Journal of the Experimental Analysis of Behavior, 45, 237-256. doi:10.1901/ jeab.1986.45-237
Malott, R. M. (1989). Achievement of evasive goals. In S. C. Hayes (Ed.), Rule governed behavior: Cognition, contingencies, and instructional control (pp. 153-190). New York: Plenum.

Matos, M. A. (2001). Comportamento governado por regras. Revista Brasileira de Terapia Comportamental e Cognitiva, 2, 51-66.

Matsuo, G. L., Albuquerque, L. C., \& Paracampo, C. C. P. (2014). Efeitos de justificativas relatadas em regras sobre o seguimento de regras. Acta Comportamentalia, 22, 273-293.

Najjar, E. C. A., Albuquerque, L. C., Ferreira, E. A. P., \& Paracampo, C. C. P. (2014). Efeitos de regras sobre relatos de comportamentos de cuidados com os pés em pessoas com diabetes. Psicologia: Reflexão e Critica, 27, 341-350.

Newman, B., Buffington, D. M., \& Hemmes, N. S. (1995). The effects of schedules of reinforcement on instruction following. The Psychological Record, 45, 463-476.

Okoughi, H. (1999). Instructions as discriminative stimuli. Journal of the Experimental Analysis of Behavior, 72, 205-214. doi:10.1901/ jeab.1999.72-205

Paracampo, C. C. P., Albuquerque, L. C., Carvalló, B. N., \& Torres, S. M. (2009). Análise do controle por regras apresentadas em histórias infantis. Revista Brasileira de Análise do Comportamento, 5, 107-122. doi:http://dx.doi.org/10.18542/ rebac.v5i2.933

Paracampo, C. C. P., Albuquerque, L. C., Mescouto, W. A., \& Farias, A. F. (2013). Efeitos de perguntas e de respostas às perguntas sobre o seguir regras. Psicologia: Teoria e Pesquisa, 29, 63-74.

Schlinger, H., \& Blakely, E. (1987). Function-altering effects of contingency-specifying stimuli. The Behavior Analyst, 10, 41-45.

Schlinger, H., \& Blakely, E. (1994). A descriptive taxonomy of environmental operations and its implications for behavior analysis. The Behavior Analyst, 17, 43-57.

Skinner, B. F. (1957). Verbal behavior. Acton, MA: Prentice Hall.

Skinner, B. F. (1963). Operant behavior. American Psychologist, 18, 503-515.

Skinner, B. F. (1966). An operant analysis of problem solving. In B. Kleinmuntz (Ed.), Problem solving: Research, method and teaching (pp. 271344). New York: Wiley. 
Skinner, B. F. (1969). Contingencies of reinforcement: A theoretical analysis. New York: Appleton-Century-Crofts.

Skinner, B. F. (1974). About behaviorism. New York: Alfred A. Knopf.

Skinner, B. F. (1981). Selection by consequences. Science, 213, 501-504.

Skinner, B. F. (1989). Recent issues in the analysis of behavior. Columbus, $\mathrm{OH}$ : Merrill Publishing Company.

Vargas, E. A. (1988). Verbally-governed and eventgoverned behavior. The Analysis of Verbal Behavior, 6, 11-22. doi:https://doi.org/10.1007/ BF03392825

Wulfert, E., Greenway, D. E., Farkas, P., Hayes, E. C., \& Douguer, M. J. (1994). Correlation between self-reported rigidity and rule-governed insensitivity to operant contingencies. Journal of Applied Behavior Analysis, 27, 659-671. doi:10.1901/jaba.1994.27-659
Zettle, R. D., \& Hayes, S. C. (1982). Rule-governed behavior: A potential theoretical framework for cognitive-behavior therapy. In P. C. Kendall (Ed.), Advances in cognitive-behavioral research and therapy (pp. 73-118). New York: Academic Press.
Recebido: 31/03/2016

$1^{a}$ revisão: $13 / 10 / 2016$

$2^{a}$ revisão: $21 / 10 / 2016$

$3^{a}$ revisão: $16 / 11 / 2016$

$4^{a}$ revisão: $19 / 12 / 2016$

Aceite final: 28/12/2016 